\section{Um jogo de regras sociais}

\section{A game of social rules}

Thaiane Moreira de Oliveira ${ }^{[a]}$, Emmanoel Martins Ferreira ${ }^{[b]}$

\section{Resumo}

Este trabalho tem por objetivo apresentar um mapeamento sobre as práticas sociais existentes e necessárias para a vivência da experiência em Jogos de Realidade Alternada. Defendemos que, embora este seja um gênero de jogo que não possui regras bem definidas, existem regras implícitas e explícitas que dizem respeito aos comportamentos sociais dos interatores, necessárias para a interação entre os jogadores e seus pares. Defendemos, ainda, que tais regras não se aplicam unicamente aos jogadores em si, mas compõem a relação entre estes e os produtores deste gênero de jogo. Para tanto, como aporte metodológico utilizamos observação
Jornalista, doutoranda em Comunicação do Programa de Pós-Graduação da Universidade Federal Fluminense (UFF), Niterói, RJ-Brasil, e-mail: thaiane.moliveira@gmail.com

[b] Graduado em Desenho Industrial, doutor em Comunicação e Cultura pela Escola de Comunicação da Universidade Federal do Rio de Janeiro (UFRJ), professor adjunto do Departamento de Estudos Culturais e Mídia da Universidade Federal Fluminense (UFF), Rio de Janeiro, RJ- Brasil, e-mail: emmanoferreira@gmail.com
Palavras-chave: Games

studies. Cibercultura. Jogos.

Práticas sociais. 
participante, juntamente com outras práticas metodológicas, como entrevistas informais por e-mail e presença nos live actions, entre os anos de 2009 a 2012, a fim de investigar as interações entre os jogadores em diversas produções deste gênero de jogo, observando grande parte dos espaços sociais existentes nos jogos de realidade alternada.

\begin{abstract}
This paper aims to present a mapping about an existing social practices and necessary to the experience in Alternate Reality Games. We defend that this is a genre of game that does not have well-defined rules, but there are implicit and explicit rules that relate to the conduct of social interactors, necessary for the interaction between players and peers. We argue further that such rules do not apply only to the players themselves, but make the relationship between them and the producers of this genre of game. Therefore, as the methodological approach we used participant observation, along with other methodological practices such as informal interviews by email and presence in live actions between the years 2009 to 2012 in order to investigate the interactions between players in different productions of this game genre, noting much of the social spaces that exist in alternate reality games.
\end{abstract}

Keywords: Games studies. Cyberculture. Games. Social practices.

\section{Introdução}

Este trabalho tem como objetivo apresentar um mapeamento sobre as práticas sociais observadas durante a interação com os jogadores de Alternate Reality Games, durante os anos de 2009 a 2012. Para tanto, foi necessário frequentar diversos canais de comunicação com esses jogadores, sobretudo, nas comunidades do Orkut utilizadas como espaço de sociabilidade, até então. Os jogos nos quais houve atuação enquanto observação participante foram: "A fórmula do conhecimento" (2009), "Os guardiões" (2009), "Caçadores de energia" (2010-2011) e "Sentinela do 
Trapiche" $(2012)^{1}$. Os canais de sociabilidade foram o Orkut, exceto em "Sentinelas do Trapiche", em que a interação ocorreu tanto nessa rede, quanto no Facebook.

Durante o período observado, buscou-se participar minimamente durante os anos de 2009 e 2010, a fim de captar as formas de sociabilização dos integrantes nas comunidades virtuais. Em 2011, a participação passou a ser mais atuante, não apenas nos espaços virtuais como também nos live actions ${ }^{2}$, no Rio de Janeiro, como no Centro Cultural Banco do Brasil e Riocentro, ações dos jogos "Sentinelas do Trapiche" e "Caçadores de energia", respectivamente. Escolhemos adotar tal procedimento que confere uma negociação entre o pesquisador e o pesquisado, participando em tais espaços mais como investigador do que como jogador, sem contudo deixar de interagir nos respectivos canais de comunicação trazendo questões não apenas ingame como também da própria pesquisa. Tal postura adotada vai ao encontro dos princípios da observação participante traçada por William Foote Whyte:

A observação participante, implica, necessariamente, um processo longo. Muitas vezes o pesquisador passa inúmeros meses para "negociar" sua entrada na área. Uma fase exploratória é, assim, essencial para o desenrolar ulterior da pesquisa. O tempo é também um pré-requisito para os estudos que envolvem o comportamento e a ação de grupos: para se compreender a evolução do comportamento de pessoas e de grupos é necessário observá-los por um longo período e não num único momento (WHYTE, 2005, p. 320).

Diante disso, foram necessários anos de interação esporádica e observação densa entre as comunidades de jogos. Além da observação participante, também foram realizadas entrevistas em profundidade durante os live actions e por e-mail, durante o período de análise. Tais entrevistados foram escolhidos com base nos seguintes critérios: acessibilidade e disponibilidade para fornecer essas longas conversas informais - um dos princípios propostos por Whyte $(2005$, p. 301) - e, principalmente, o nível de atuação dos mesmos nas comunidades de compartilhamento de informação sobre o jogo. Todos os entrevistados poderiam ser

\footnotetext{
1 Cabe ressaltar, ainda, que houve um estudo em profundidade a partir do jogo "Zona Incerta" (2007) como objeto de pesquisa sobre configurações das competências cognitivas no processo de sociabilidade nos Alternate Reality Games. Tal estudo foi basilar para observação sobre as práticas sociais em outros jogos do gênero.

2 Como são chamadas as ações nos espaços urbanos.
} 
enquadrados como "entusiastas", segundo categorização realizada pela 42 Enterteinment, grande produtora desse gênero de jogo, como mostra a Figura 1.

Convém ressaltar ainda que não houve necessidade de um intermediário neste estudo de campo. Contudo, como os Alternate Reality Games são um gênero de jogo, surgido em 2001, que transita entre as fronteiras da realidade e da ficcionalidade, os jogadores cogitaram num momento inicial (2009) que a pesquisa fazia parte de um jogo. Contudo, tal fato foi contornado apresentando resultados iniciais da coleta, além de apresentar ao grupo desconfiado o relacionamento profissional com um jogador, e também pesquisador da área. A partir dessa interlocução, a interação nas comunidades tornou-se mais fluida e legitimamente reconhecida.

Cabe ressaltar, ainda, que as informações que serão apresentadas são os dados coletados durante o período e não análises sobre esses resultados, visto que a etnografia nem sempre requer uma conclusão sobre as relações sociais

O Alternate Reality Game (ARG) é um tipo de jogo muito peculiar com características próprias, dinâmicas adaptáveis ao meio e com regras

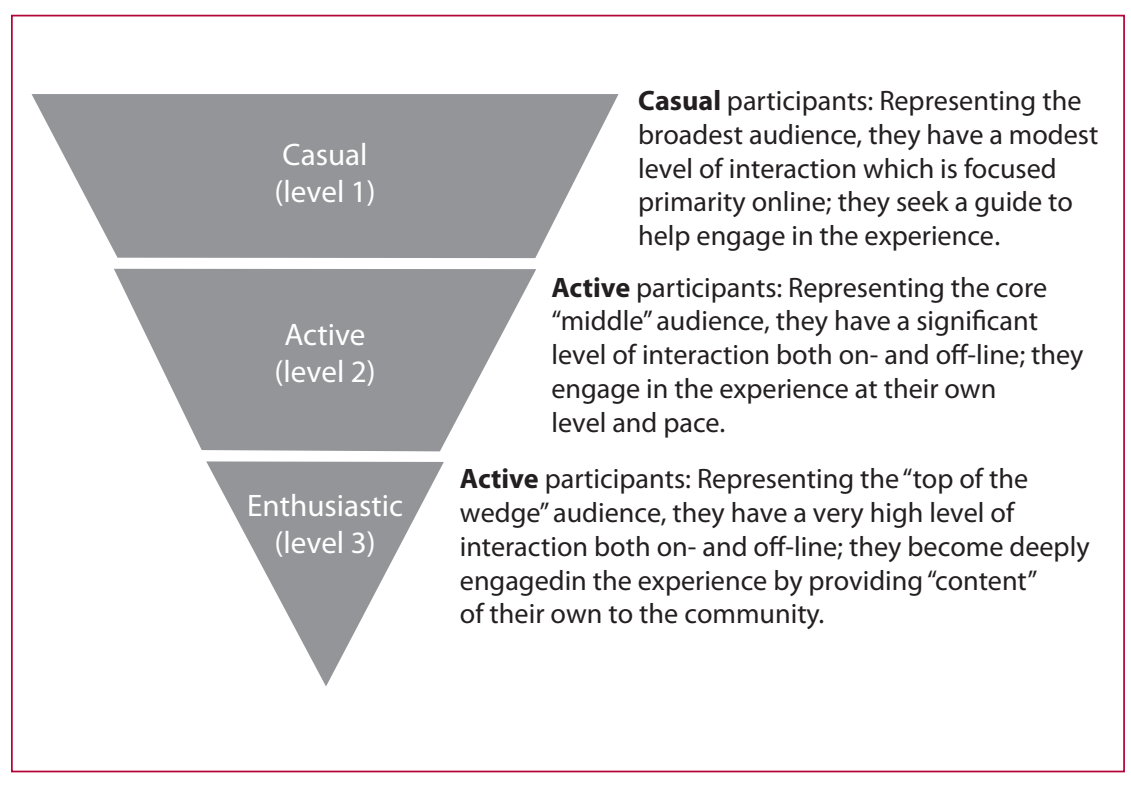

Figura 1 - Pirâmide invertida da 42 Enterteinment sobre a atuação de jogadores de Alternate Reality Game Fonte: Extraído da página web 42ENTERTAINMENT³.

${ }^{3}$ Disponível em: <http://www.42entertainment.com>. Acesso em: 14 jul. 2013. 
flexíveis. É um jogo que tem como eixo uma narrativa central fragmentada e que tende a utilizar, além da internet, diversas plataformas e dispositivos, inclusive o próprio espaço urbano para distribuição dos puzzles e enigmas do jogo. Sua estrutura envolve diferentes ferramentas de comunicação - e-mails, mídias sociais, SMS, websites, telefonia móvel etc. - utilizadas para conectar personagens, interpretados por atores, e jogadores em um universo ficcional, no qual o público deve resolver quebra-cabeças, investigar mistérios, dentre outros desafios, para avançar na narrativa transmidiática que dispersa os elementos em diversos canais (OLIVEIRA; ANDRADE, 2010).

Dan Provost define o ARG como:

Uma narrativa interativa que usa o mundo real como plataforma, muitas vezes envolvendo vários meios de comunicação e os elementos do jogo, para contar uma história que pode ser afetada por ideias ou ações de participantes. Todos os jogadores estão intensamente envolvidos na história que acontece em tempo real e não pode ser repetida. A narrativa se desenvolve com base na interação dos jogadores e com tudo o que é projetado e controlado por humanos, ao invés de um computador ou a inteligência artificial [como seria o caso de um jogo tradicional de computador ou de consoles] (PROVOST, 2008, p. 2, tradução nossa).

Dan Provost considera os ARGs como a primeira forma de arte narrativa metaficcional nativa para a internet, que "borra" a linha tênue entre a ficção e a realidade e frequentemente requer por sua complexidade o uso de inteligência coletiva para resolver os enigmas que são projetados. Segundo o Alternate Reality Game Network (ARGNet), site colaborativo de feeds de notícias sobre ARGs, jogos pervasivos e afins, os jogos de realidade alternada são:

Um inspirador gênero de jogo que mistura caça ao tesouro da vida real, histórias interativas, jogos de vídeo e comunidade on-line... Estes jogos são uma intensa série de complicados enigmas que envolvem sites codificados, pistas no mundo real como anúncios em jornais, telefonemas no meio da noite de personagens de games e muito mais. [...] Estes jogos (que geralmente são livres para jogar) muitas vezes têm um objetivo específico, não só envolvendo o jogador com a história e/ou personagens de ficção, mas de conectá-los ao mundo real e uns aos outros (ALTERNATE REALITY GAMING NETWORK, 2002-2006 apud EYLES; EGLIN, 2008, p. 5, tradução nossa). 
A premissa desse jogo é o Tinag (This Is Not A Game) e consiste em o jogador fingir que não é um jogo a fim de uma maximização da sua experiência no processo de jogar os Alternate Reality Games. Parte da diversão do público em participar de desafios dos ARGs é encarar a experiência como se ela não fosse intitulada "jogo". Nesse caso, a sigla Tinag é um lembrete fácil para demarcar as fronteiras entre o que é realidade e ficção, durante a experiência, refletindo o envolvimento ou a imersão dos jogadores no universo criado pelo ARG.

Os ARGs são considerados uma subcategoria dos jogos pervasivos ou, segundo Jane McGonigal (2006), ubiquitous games, gênero de game que busca transcender suas ações para além do suporte material mediador entre o jogador e o programa, explorando tanto os espaços virtuais eletrônicos quanto os espaços físicos urbanos da realidade concreta ${ }^{4}$. Originados dos Role-Playing Games (ANDRADE, 2008), cuja tradução para o português se aproxima de "jogo de interpretação de personagens", os ARGs são considerados o quarto estágio do RPG ${ }^{5}$ como discorreremos a seguir, buscando enquadrar o contexto histórico capaz de abranger particularidades e características pertinentes a esse gênero de game.

\section{Os quatro estágios dos Role-Playing Games}

O primeiro estágio são os RPGs de mesa, onde há a figura do mestre e dos jogadores que vivenciam a experiência a partir de regras pré-definidas pelo mestre, com base no livro-jogo, em uma construção colaborativa do universo diegético em torno da aventura. A experiência do RPG acontece unicamente no mundo concreto e os jogadores interagem a partir de encenação teatral de personagens.

Os RPGs surgiram em 1974, com o jogo Dungers and Dragon, produzido por Gary Gygax e Dave Arneson. A partir deste jogo, que se transformou em uma febre entre as décadas de 1970 e 1980, foram criados diversos filmes como Mazes and Monsters, em 1983, e Dungers and Dragons, em 2000, no desenho animado Caverna do Dragão, jogos eletrônicos, além de

4 É importante ressaltar que, apesar de ser apresentada como estágios do RPG, essa classificação não demarca fronteira de evolução, na qual o estágio seguinte invalida a existência do estágio anterior.

5 Como a distinção entre os conceitos de pervasivos e ubiquitous ainda não se tornou senso comum, preferimos adotá-los como sinônimos, utilizando apenas o termo "pervasive" para nos referir a esse gênero de jogo que transborda seus elementos para o mundo comum. 
uma série de fansfilms distribuídos em redes e canais. Tal fato demonstra a potência crossmedia que esse gênero de jogo pode desenvolver.

Uma variação dos RPGs são os LARPs, Live Action Role-Playing Games. A diferença entre o RPG e o LARP consiste em dois aspectos. No LARP os jogadores encenam fisicamente os personagens (TYCHSEN et al., 2006) e existe uma ambientação ficcional criada para tal fim que pode ser realizada tanto em espaços públicos como em espaços fechados (SALEN; ZIMMERMAN, 2003).

Os LARPs surgiram no final da década de 1970 e consistem em uma encenação improvisada, com vestimentas e cenografias ambientadas conforme o jogo do RPG (que pode ter variações temáticas medievais, futuristas, épicas, entre outras). Os jogadores compartilham a experiência de representação e exploração de um universo diegético criado a partir de uma ambientação ficcional e inventam coletivamente seus próprios arcos narrativos durante o jogo. Janet Murray (2003, p. 53) considera que:

Os jogos de representação são teatrais de um modo não convencional, mas emocionante. Os jogadores são, ao mesmo tempo, atores e espectadores uns para os outros, e os eventos que eles encenam frequentemente possuem o imediatismo das experiências pessoais.

Esse gênero de jogo cresceu vertiginosamente nos anos 1980, chegando a se criar grupos organizados e competições. Em 1986, foi lançado o jogo GURPS como um sistema de regras adaptáveis à temática a ser escolhida pelo mestre. No Brasil, as publicações dos livros de RPG eram difíceis de ser conseguidas e essa situação só foi revertida após a abertura comercial na década de 1990.

O segundo estágio dos RPGs são transportados para os jogos de computador, criando, assim, os chamados Role-Playing Games eletrônicos, ou offline, como chamados atualmente, pelo fato de que, nessa época, ainda não havia a abertura comercial e, consequentemente, a popularização da internet. Tais produções eram voltadas para jogos eletrônicos e computadores pessoais, com desenvolvimento gráfico compatível para a época, utilizando a textualidade como suporte narrativo e as ações dos jogadores baseadas em sistemas estratégicos de jogabilidade.

Nesse tipo de jogo, já escasso atualmente, o jogador interage apenas com o software, sem haver a experiência coletiva dos RPGs, porém "é mantida a característica de incorporar papéis em mundos ficcionais" (ANDRADE, 2008, p. 136). 
O terceiro estágio surge em consequência da abertura comercial da internet, em meados dos anos 1990, e comporta, dessa forma, a experiência de jogar coletivamente. São os chamados Multiuser Massive Online Role-Playing Games, gênero de jogo que continua a fazer sucesso até os dias atuais e objeto de estudo e interesse para a academia.

Com o avanço e domínio das novas tecnologias de computação, os designs gráficos dos MMORPGs avançaram e puderam ser criados ambientes digitais complexos, com dispositivos e ferramentas que permitem uma interação entre usuários. Dessa interação, podem-se formar comunidades cujo objetivo é não apenas comunicacional e de entretenimento e sociabilidade, mas também o de dar suporte para esclarecimento de dúvidas e discutir estratégias a fim de melhorar o desempenho do jogo e fortalecer seus avatares.

Os MMORPGs têm como preconizador os Multiuser Domains, também chamados de MUDs, surgidos na década de 1970, porém com uma interface ainda em desenvolvimento. Nos MUDs já existia a possibilidade de criação de ambientes colaborativos, no entanto ainda com limitações relacionadas aos suportes textuais.

Existem algumas características que diferenciam os Role-Playing Games, Massive Multiple Online Role-Playing Games e os Alternate Reality Games. Um fator fundamental que os diferencia se refere à temporalidade da imersão nesses jogos. Nos MMORPGs, o jogador fica imerso no jogo durante a sua permanência no ambiente lúdico, utilizando um aplicativo personalizado a ser rodado diretamente no computador do jogador, o qual pode se ausentar do ambiente e retornar ao ponto em que parou. Já nos ARGs não há um aplicativo de software a ser manuseado pelo jogador. As pistas são fragmentadas e distribuídas em vários meios e canais, como sites, blogs e redes, celulares, e-mails, espaços urbanos etc. Pelo fato de o ARG ser jogado em coletividade, caso o usuário interator se ausente, o jogo continuará acontecendo; as pistas serão fornecidas e desvendadas e a narrativa continuará a ser discorrida. Assim, o jogador que se ausentou terá que recuperar o que foi discutido e desvendado através de mecanismos documentados, geralmente nos locais virtuais, como comunidades e fóruns criados para fins de compartilhamento de informações, pelos outros jogadores. Tal fato não compromete a imersividade do jogador com o jogo, mas a incute a um espectro de temporalidade que estimula o interator a retornar ao jogo periodicamente, com intervalos mais curtos do que um jogador de MMORPG, que tem total controle do aplicativo. 
No RPG, os jogadores personificam e encenam um personagem predeterminado, enquanto nos MMORPGs os jogadores criam no software avatares para a vivência do jogo. Já nos Alternate Reality Games, o jogador é personagem de si. Não há outra personificação, salvo experimentações de personalidades para além das vivenciadas cotidianamente pelo jogador.

Roger Tavares (2004) acredita que o jogador de jogos eletrônicos apresenta um desejo de se unificar ao sistema operacional no ato de criação de um avatar como modelo de representação de si, diferentemente de quando escolhe um personagem já estabelecido para o jogo. Para o autor, o jogador:

quer usufruir de tudo o que o sistema pode lhe oferecer: superpoderes, supervisão, vida infinita, exploração de mundos e labirintos sem fim. Nem que ele tenha que minimizar a sua personalidade em relação à da personagem, ser castigado por não conseguir a coordenação motora necessária, ser obrigado a resolver questões que, às vezes, não têm o menor interesse, mas ele quer estar participando, subjetivando-se dentro de uma experiência imersiva e potencializadora (TAVARES, 2004, p. 218).

O autor acredita que, por meio da criação de um avatar, haja a possibilidade de uma simbiose de descorporificação e recorporificação ciborguizante. Contudo, no ARG, os jogadores são personagens de si (SHELDON, 2010, p. 248). Como há uma fusão entre o real e o ficcional, o ARG-player interpreta a si mesmo durante os lives actions. A essa interpretação podemos atribuir parte da imersão imaginativa, proposta por Laura Ermi e Frans Mäyrä.

Chamamos esta dimensão de experiência de jogo em que a pessoa se torna absorvida com as histórias e com o mundo, ou começa a se sentir ou se identificar com um personagem do jogo, de imersão imaginativa. Esta é a área na qual o jogo oferece ao jogador a chance de usar sua imaginação, criar empatia com os personagens, ou simplesmente desfrutar da fantasia do jogo (ERMI; MÄYRÄ, 2005, p. 8, tradução nossa).

Para os autores, jogos com personagens e enredos em que os jogadores têm mais possibilidades de se identificar com algo são mais capazes de propiciar a imersão imaginativa. Já Dominic Arsenault (2005) propõe 
uma releitura sobre o modelo estruturado por Laura Ermi e Frans Mäyrä, trocando o conceito de imersão imaginativa por imersão ficcional. Para o autor, a imersão imaginativa seria muito ampla e estaria condicionada à imersão ficcional.

A imersão imaginativa seria basilar no processo de jogar um ARG ou qualquer outro gênero de jogo cuja gameplay se dá por meio de representação de personagens; a identificação dos papéis e o processo mental da imaginação são parte do "fingimento" de não ser um jogo para uma maximização de suas experiências.

A esse fenômeno de "fingimento" Jane McGonigal (2003) chama de "efeito Pinóquio", no qual os jogadores suspendem voluntariamente sua descrença, não se importando com a inserção de elementos não diegéticos ao jogo. A autora afirma que esse fingimento é uma decisão consciente para prolongar os prazeres da experiência, uma vez que o fingimento ativo de crença propicia oportunidades de participação e colaboração, ignorando todos os elementos metacomunicacionais que poderiam indicar as fronteiras físicas temporais e sociais do que é jogo.

Longe de qualquer tipo de passividade, essa escolha intencional, a que Murray chama de "criação ativa da crença", é o combustível para a imersão no ambiente ficcional:

Quando entramos em um mundo ficcional, fazemos mais do que suspender uma faculdade crítica; também exercemos uma faculdade criativa. Não suspendemos nossas dúvidas tanto quanto criamos ativamente uma crença. Por causa do nosso desejo de vivenciar a imersão, concentramos nossa atenção no mundo que nos envolve, usamos nossa inteligência mais para reforçar do que para questionar a veracidade da experiência (MURRAY, 2003, p. 111).

Em outras palavras, diante das abordagens aqui explicitadas, podemos perceber que essa atividade dos jogadores em prol de sua experiência imersiva os leva a um constante ajuste intencional cognitivo a fim de mantê-los mais próximos da realidade dentro do próprio ambiente ficcional, pois, caso contrário, a sua imersão os condicionaria a um "afogamento" na diegese. Nas palavras de Ryan (2001, p. 97), "o oceano é um ambiente em que não podemos respirar; para sobreviver à imersão, devemos levar oxigênio a partir da superfície, ficar em contato com a realidade"; ou seja, esse contato direto com a realidade é uma mediação de ajuste cognitivo elaborada pelos próprios jogadores no decorrer de sua experiência imerso-pervasiva que pode durar até meses. Nesse período, 
o contato gradual com o círculo mágico fica subordinado à temporalidade do "mundo ordinário", isto é, os jogadores, mesmo sem estarem exercendo o gameplay, enquanto fora do ingame, no mundo ordinário de suas vivências concretas, voluntariamente pensam em maneiras de resolver um puzzle ou postar alguma hipótese sobre o game nos fóruns de discussão.

Para maior compreensão do fenômeno das relações sociais e competências cognitivas individuais desses jogadores, vale mencionar uma pesquisa realizada por Silva (2008), em que foram entrevistados 153 jogadores e, a partir da aplicação de um questionário, em que se verificou o perfil do público-alvo desse gênero de game. Segundo Silva (2008), 53\% dos jogadores acessam a internet mais de 4 horas por dia e, do total de entrevistados, $80 \%$ costumam jogar outros tipos de jogos do meio digital. Silva ainda destacou que os jogadores de ARG pertencem a uma faixa etária que varia de 16 a 35 anos. Tal constatação da faixa etária apontada por Silva também nos faz refletir sobre as gerações de nativos e imigrantes digitais, segundo a abordagem de Marc Prensky (2001).

$\mathrm{O}$ autor defende que os chamados nativos digitais apreendem de forma não linear devido às imersividades propiciadas pelas novas tecnologias de comunicação e informação que estão em sua volta. Cabe ressaltar que, apesar de certa contribuição para a área da educação, Marc Prensky delimita a forma de aprendizado dessa geração como se esta não se relacionasse com o mundo salvo pelas telas de computadores; o autor ignora uma série de outras questões socioculturais, como o meio e as relações políticas, como poder aquisitivo, acesso às tecnologias e inclusão digital.

Diante dos dados coletados por Silva (2008), podemos concluir que esses grupos de jogadores são formados pelas gerações de nativos e imigrantes digitais. Isso demonstra que não há uma particularidade geracional de acordo com tais categorias e, sim, que sua composição é mais calcada no interesse de determinadas pessoas em vivenciar a experiência e não o seu acesso tecnológico desde seu desenvolvimento.

\section{Regras do gameplay}

As dinâmicas nesses ambientes acontecem na forma de experiências sociais que circulam por diversos contextos colaborativos. Tal como em outros jogos, existem regras inerentes aos ARGs, porém, por se tratar de 
um jogo dinâmico em que o mistério é elemento surpresa que propicia o engajamento do jogador, suas regras estão em constante adaptação, tal como defende Szulborski (2005, p. 58, tradução nossa):

\begin{abstract}
Um jogo de realidade alternada tem regras, mas elas não são definidas e escritas em qualquer lugar. Em vez disso, o jogador aprende as regras mediante sua observação e interação com o jogo. Dessa forma, os jogos de realidade alternativa são uma forma muito especial de jogo, lançando o conceito restritivo de regras definidas.
\end{abstract}

Acrescentando à constatação de Szulborski, podemos observar que as regras se dão apenas na relação do ARG-player com o jogo e com outros jogadores, interagindo diretamente com os personagens e trabaIhando em conjunto com outros membros da comunidade na resolução dos enigmas e dos puzzles em uma competição para alcançar determinados objetivos do jogo (McGONIGAL, 2006). Uma das primeiras metas de um ARG é descobrir quem são os puppetmasters ${ }^{6}$, quem compõe a base de game designers, qual é a empresa ou o produto que realiza a criação do jogo, ou seja, quem está por trás da cortina que separa o jogador do universo ficcional. Essa é uma espécie de sondagem inicial que é realizada pelos jogadores, concomitante ao desenvolvimento das resoluções dos puzzles iniciais, que permitem um mapeamento intuitivo do cerne da narrativa, como afirmou Sosô Targa, uma das jogadoras e entusiastas, em conversa informal pelo chat do Facebook7, "achar a base é uma das nossas principais diversões".

Em sua natureza, este é um jogo essencialmente colaborativo visto que a complexidade de seus enigmas e a narrativa fragmentada estimulam a participação dos jogadores em comunidades a fim de, conjuntamente, resolver os puzzles propostos e dar continuidade ao jogo. Nesse sentido, é muito comum vermos atitudes como as da Figura 2, em que o compartilhamento de informações são feitos a partir do princípio de colaboração e, sobretudo, reconhecimento entre os pares.

E nesse âmbito de cooperação e colaboracionismo as interações sociais tornam-se fator primordial para o funcionamento do ARG. Nesse âmbito colaborativo compartilhado por objetivos em comum, regras de interações

\footnotetext{
6 Como são chamados os produtores de ARG - também chamado de "base" - em alusão aos titereiros de fantoche.

7 Conversa informal realizada no chat do Facebook durante interação do grupo do jogo "Sentinelas do Trapiche", 2011.
} 
sociais são construídas nessa relação do interator com o jogo, com os outros jogadores e com o mundo comum que os cerca, sendo este último também parte do próprio game, um grande tabuleiro no qual eles estão inseridos e que são peças fundamentais (MONTOLA; STENROS; WAERN, 2009).

Segundo Björk e Holopainen (2005, p. 259, tradução nossa), a "interação social é quando dois ou mais jogadores têm uma comunicação bidirecional entre si, ou seja, os outros jogadores podem responder à comunicação do jogador individual". De acordo com os autores, os jogos com a interação social alta muitas vezes contam com os jogadores para poder colaborar e não apenas para competir uns contra os outros. Dessa forma, a interação se dá em alguns padrões de comportamento por intermédio de incentivos projetados pelo game designer, como compartilhamento de recompensas ou recompensas individuais.

ARGs raramente têm um único vencedor ou um momento em que você, como jogador individual, na verdade, luta ou opõe-se ao último inimigo e derrota-o. ARGs são principalmente experiências coletivas em que você, como membro de um grupo de jogadores, trabalha em conjunto para resolver os mistérios e acabar com os conflitos dentro do jogo. Portanto,

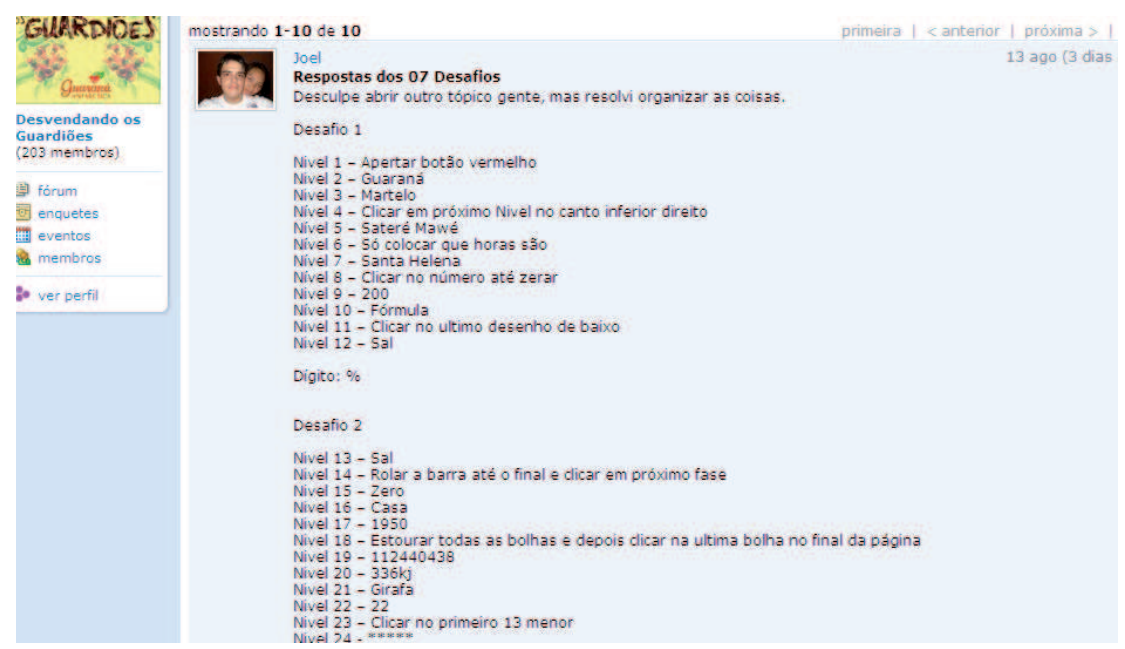

Figura 2 - Compartilhamento das resoluções dos puzzles do game "Os guardiões", 2011 Fonte: Print screen da página web do Orkut ${ }^{8}$.

8 Disponível em: <http://www.orkut.com.br/Main\#Community?cmm=92019302>. Acesso em: 14 de jul. 2013. 
não é um momento 'yeehaw!' em que você ultrapassa o sujeito mau e vê alguma forma de representação simbólica de 'Você venceu! Game Over' na tela. Em vez disso, ainda que, mesmo se um único ou poucos jogadores são fundamentais para resolver alguns puzzles finais ou realizar alguma tarefa, normalmente é a comunidade que compartiIha a sensação de 'missão cumprida', quando o jogo chega ao fim (SZULBORSKI, 2005, p. 68, tradução nossa).

Uma das regras de interação social necessária para o funcionamento do ARG refere-se ao respeito pelo Tinag. No Brasil, os jogadores, para expressarem suas articulações, criam estruturas simbólicas de linguagem Tinag Mode On e Off - e as inserem no início de algumas postagens. Utilizam (Tinag On), quando aludem à representação ficcional da narrativa, ou postam (Tinag Off), a fim de se referirem a elementos externos ao jogo, como comentários sobre as produções do game, por exemplo, como ilustrado na Figura 3.

Tal estratégia de comunicação é uma forma de estar em constante contato com a realidade, evitando assim possíveis afogamentos diegéticos através de um comportamento de sociabilização, um processo em que a linguagem ocupa papel fundamental de produção de saberes dos jogadores.

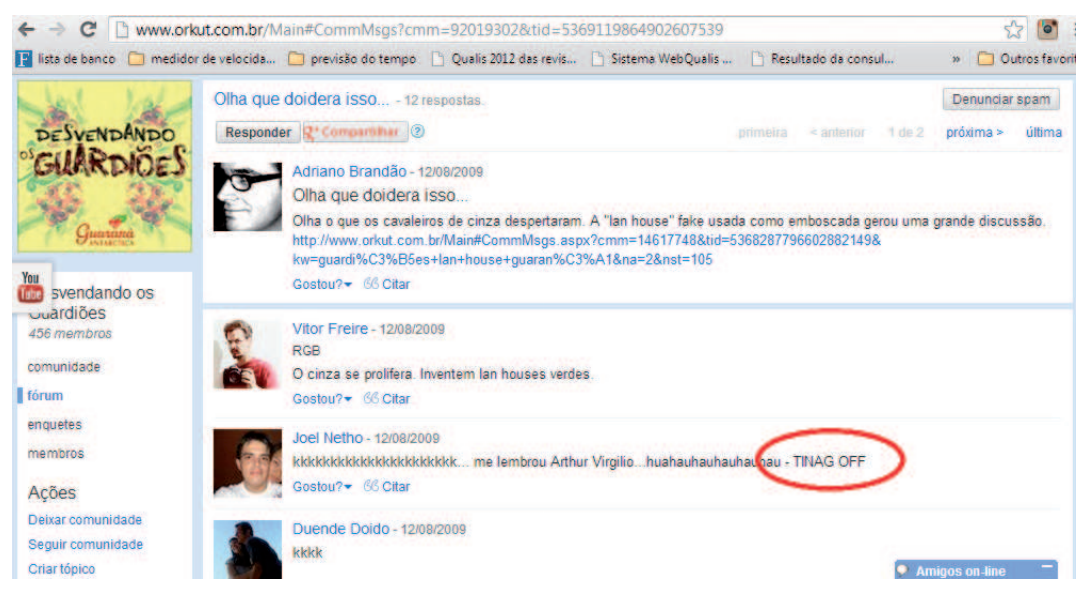

Figura 3 - Tinag [ON] [OFF] - Comunidade do ARG "Os guardiões", 2009 Fonte: Print screen da página web do Orkut ${ }^{9}$.

${ }^{9}$ Disponível em: <http://www.orkut.com.br/Main\#Community?cmm=92019302>. Acesso em: 14 jul. 2013. 
Os sujeitos se produzem, enquanto produzem, trocam, se comunicam. A linguagem será então o instrumento comum a todos os mediadores do imaterial. A linguagem organiza os saberes, a comunicação e a cooperação sobre as bases do entendimento e dos sensos [...]. Toda socialização traz um caráter, embutido, de internalização das normas sociais. É o preço que o indivíduo deve pagar, para evitar uma existência marginalizada, caso queira incluir-se. E essas normas sociais carregam seus discursos inclusivos, que se produzem, difundem, circulam e se recebem por processos de semiose ilimitada (ATEM, 2008, p. 6, grifo do autor).

A partir da fala de Guilherme Nery Atem, é possível inferir que os sujeitos se produzem enquanto signos nesse processo de sociabilização por intermédio de signos linguísticos explicitados no compartilhamento de informações das redes sociais.

Outros padrões de comportamentos sociais das atividades em grupo presentes nos ARGs, seguindo a visão de Björk e Holopainen sobre jogos de interação social, são a distribuição de áreas de competência para cada jogador, alianças entre os jogadores formadas por laços de afinidade e formação de equipe, coordenando suas ações, habilidades e papéis a fim de alcançar um objetivo comum (BJÖRK; HOLOPAINEN, 2005, p. 247). Em graus de constância menor, ainda é possível observar negociações de informações e blefes (BJÖRK; HOLOPAINEN, 2005, p. 262, 269), sendo essas condutas adotadas por jogadores individuais que são passíveis de rejeição da própria comunidade". Outra conduta passível de rejeição pelo grupo é a "preguiça" de inteirar-se sobre o que já fora discutido anteriormente, sobretudo com jogadores que ainda não foram legitimados pelo grupo, como observado na Figura 4.

Alguns ARGs possuem a oferta de recompensas materiais como forma de incentivo ao jogo, porém estas não são necessárias para um bom desenvolvimento do mesmo, visto que a primazia pela experiência é preponderante entre os jogadores, tal como será demonstrado posteriormente. Dessa forma, as recompensas são muito mais subjetivas e estão presentes no compartilhamento de experiências entre os pares. Contudo, tal colaboracionismo está imbuído de resquícios de uma busca por prestigio entre a comunidade de players, pelo alcance de um status social na medida em que o jogador é admirado, estimado ou aprovado pelos outros jogadores do jogo, bem como por pessoas fora do jogo (BJÖRK; HOLOPAINEN, 2005, p. 269). Ou seja, por mais coletivo que este gênero de jogo seja, as demandas subjetivas individuais permanecem expressas tal como em qualquer outra esfera social. 
Sendo assim, apesar de o Alternate Reality Game ser jogado em coletividade e de não haver a prerrogativa da competitividade entre os participantes (como quando apenas um jogador pode ser o vencedor), existe uma tendência no Reality Game em que o estímulo ao colaboracionismo nada mais é que uma oportunidade de a individualidade se expressar. Bryan Alexander ressalta que a emoção de desvendar as peças enigmáticas e complexas de um ARG implica realizações individuais e que "o processo de jogar esse tipo de jogo colaborativo é também uma celebração da individualidade" (ALEXANDER, 2006, p. 13, tradução nossa).

Aprofundando esse argumento de Alexander, podemos perceber que a competitividade é apresentada em formatos menos explícitos que em um jogo competitivo em si, porém se tornam visíveis quando observamos que existe uma necessidade de ser o primeiro a desvendar uma peça ou enigma, pois o jogador posta, imediatamente, a sua descoberta nas comunidades destinadas a debates do jogo. Esse desejo nasce de uma necessidade de ser visto, uma congratulação a partir da subjetividade de ser reconhecido entre seus pares.

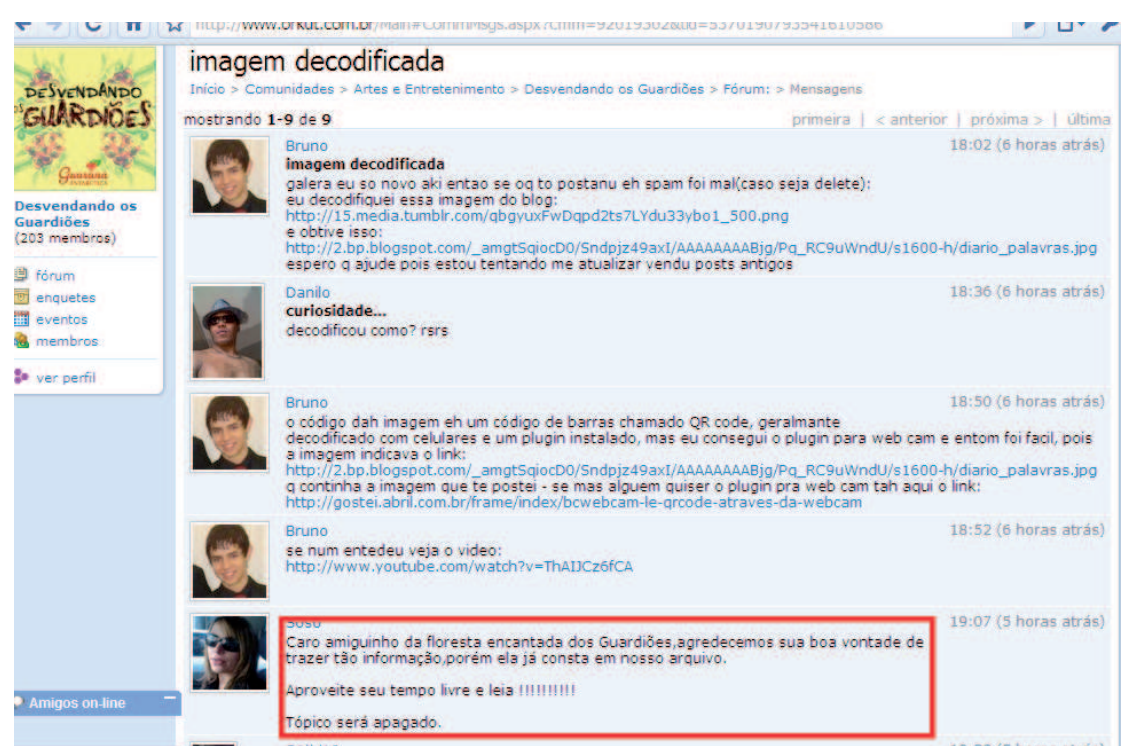

Figura 4 - Imagem retirada da Comunidade do Orkut "Desvendamos os Guardiões", 2009 Fonte: Print screen da página web do Orkut $^{10}$. ${ }^{10}$ Disponível em: <http://www.orkut.com.br/Main\#Community?cmm=92019302>. Acesso em:
14 de jul. 2013. 
Tais comportamentos sociais foram identificados a partir de observação participante durante o período de 2009 a 2012 em diversos canais de comunicação entre os jogadores, desde o Orkut, nos anos de 2009 a 2011 até a migração dos usuários para a rede social do Facebook. Outros canais observados foram fóruns e espaços de comentários em plataformas de compartilhamento de vídeos. Vale ressaltar que a plataforma Orkut possui uma estrutura de organização de conteúdo que facilitava a dinâmica de interação social entre os jogadores, como organização por tópicos, fóruns de discussão, postagens de fotos e vídeos, assim como organização de documentos. Tal estrutura facilitava a interação entre os usuários. Para canais de comunicação imediata que permitia o armazenamento de conteúdo utilizavam o Messenger (MSN). Contudo, desde 2011, houve um crescimento abrupto da rede social Facebook, o que levou a migração dos usuários e um gradual desinteresse pelas comunidades da antiga rede. Durante o período de 2011 e 2012 ainda houve resistência de alguns usuários como Rei Azul (Figura 5).

Também nesse período de 2012, poucos ARGs foram produzidos, e a comunidade que servia como central de discussão passou a receber

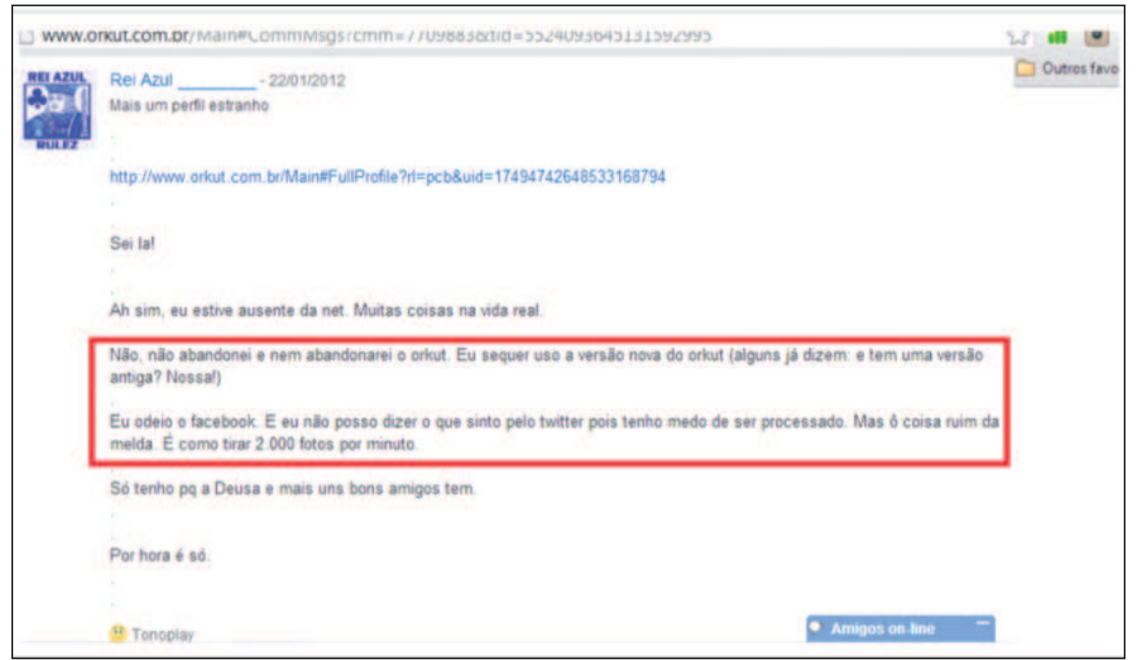

Figura 5 - Postagem na comunidade ARG do Orkut sobre a migração dos usuários para outra rede Fonte: Print screen da página web do Orkut ${ }^{11}$.

1 Disponível em: <http://www.orkut.com.br/Main\#Community?cmm=92019302>. Acesso em: 14 jul. 2013. 
esporádicas mensagens. No período de 2009 a 2013, houve uma perda de mais de mil membros. No entanto, a migração de usuários para outras redes, como o Facebook, por exemplo, não refletiu também na migração dos espaços de sociabilidade para outras plataformas. No Facebook, por exemplo, há alguns grupos destinados ao compartilhamento de informações e interação entre usuários. Porém, tais grupos não ultrapassam a quantidade de 30 membros por grupo.

Esse processo de transição ainda não está consolidado, visto que, como falado anteriormente, nesse período poucas foram as produções de ARG no Brasil. Portanto, ainda é necessário uma produção de grande porte acontecer para que possamos inferir mais conclusões sobre esta migração entre plataformas.

\section{Considerações finais}

Este trabalho teve como objetivo realizar um mapeamento das formas de sociabilidade presentes nos Alternate Reality Games. Foram investigados, a partir de observação participante, juntamente com outras metodologias como entrevistas informais por e-mail e presença nos live actions, entre os anos de 2009 e 2012, as interações em diversas produções desse gênero de jogo, observando grande parte do espaços sociais existentes nesse gênero de jogo.

Percebemos que os ARG são jogos cujas regras não são tão bem delineadas como em jogos de tabuleiro ou limitadas pelo suporte ou pela estrutura como em jogos de console. Como em todo jogo de interpretação, as regras implicam um acordo tácito - por vezes explícito, mas na maioria implícito no gameplay - entre os jogadores, seus pares e os puppetmasters. Com isso, podemos afirmar que as regras principais são regras de interação social, nas quais prevalece o bom senso e o repeito mútuo, valores indispensáveis para todas as relações. Além de valores mais gerais, existem regras acordadas que são fundamentais para que a vivência da experiência seja bem-sucedida para os jogadores, e consequentemente, para os produtores.

Podemos afirmar diante de todos os resultados aqui expostos, que não há uma conclusão final sobre o processo interacional entre os jogadores. Ao longo dessa pesquisa, a própria dinâmica foi mudando com o passar dos anos. Por exemplo, a premissa TINAG, tão cara em 2007 (ano em que houve o primeiro contato da pesquisa, mas que ainda não lhe conferia como um corpus de estudo), já não era mais tão rígida em 2011, 
apesar de ainda ser buscada e negociada constantemente pelos jogadores. A mudança de rede social, perda de interesse de muitos jogadores e a baixa produção do gênero no período também foram fatores que afetaram a dinâmica de interação social entre os jogadores, tornando-os muito mais flexíveis com as ações que não cumpriam todas as regras anteriormente necessárias para o sucesso do jogo. De certa forma, isso nos faz acreditar que o próprio meio é capaz de moldar as estruturas sociais do grupo, estando estes tão adaptáveis e flexíveis quanto às regras dos Alternate Reality Games.

\section{Referências}

ALEXANDER, B. Antecedents to alternate reality game. In: INTERNATIONAL GAME DEVELOPERS ASSOCIATION - IGDA. Alternate reality game white paper: IGDA ARG SIG. 2006. Disponível em: <http://archives.igda.org/arg/resources/IGDAAlternateRealityGames-Whitepaper-2006.pdf>. Acesso em: 11 jul. 2013.

ANDRADE, L. Realidades alternativas: novas funções cognitivas no mundo dos ARGs. In: SEMINÁRIO DE JOGOS ELETRÔNICOS, COMUNICAÇÃO E EDUCAÇÃO, 4., 2008, Salvador. Anais... Salvador: UNEB, 2008. p. 1-7.

ARSENAULT, D. Dark waters: spotlight on immersion. In: GAME ON NORTH AMERICA 2005 INTERNATIONAL CONFERENCE. 2005, Leicester, United Kingdom. Proceedings... Leicester: Montfort University, Eurosis-ETI, 2005. p. 1-7.

ATEM, G. N. O imaterial: fundamentos filosóficos-semióticos da produção de subjetividades. In: FÓRUM DE ESTUDOS LINGUÍSTICOS, 9., 2008, Rio de Janeiro. Anais.. Rio de Janeiro: Dialogarts/UERJ, 2008. p. 1-12.

BJÖRK, S.; HOLOPAINEN, J. Patterns in game design. Hingham: Charles River Media, 2005.

ERMI, L.; MÄYRÄ, F. Fundamental components of gameplay experiences: analyzing immersion. In: CHANGING VIEWS - DIGITAL GAMES RESEARCH CONFERENCE, 2005, Utrecht, Anais...Utrecht: Utrecht University, 2005. p. 1-14.

EYLES, M.; EGLIN, R. Entering an age of playfulness where persistent, pervasive ambient games create moods and modify behavior. In: INTERNATIONAL CONFERENCE ON GAMES RESEARCH AND DEVELOPMENT, 3., 10-11 September 2007, Manchester. Proceedings... Manchester, 2007. 
McGONIGAL, J. This might be a game: ubiquitous play and performance at the turn of the twenty-first century. 2006. $573 \mathrm{f}$. Thesis (Philosophy Doctorate) - University of California, Berkeley, 2006.

McGONIGAL, J. This is not a game: immersive aesthetics and collective play. In: INTERNATIONAL DIGITAL ARTS AND CULTURE CONFERENCE, 5., 2003, Melbourne, Proceedings... Melbourne: RMTI University, 2003.

MONTOLA, M.; StenROS, J.; WAERN, A. Pervasive games: theory and design. Oxford: Morgan Kaufmann Editor, 2009.

MURRAY, J. Hamlet no Holodeck: o futuro da narrativa no ciberespaço. São Paulo: Itaú cultural; UNESP, 2003.

OLIVEIRA, T.; ANDRADE, L. Um jogo de realidades e ficcionalidades. Ciberlegenda, v. 12, n. 2, jun. 2010.

PRENSKY, M. Digital natives, digital immigrants: a new way to look at ourselves and our kids. Lincoln: NCB University Press, 2001.

PROVOST, D. Metafiction and web based story telling. 2008. Disponível em: <http://a.parsons.edu/ provd139/thesis/papers/dprovost_metafiction.pdf>. Acesso em: 15 jul. 2013.

RYAN, M. L. Narrative as virtual reality: immersion and interactivity in literature and electronic media. Baltimore: Johns Hopkins University Press, 2001.

SALEN, K.; ZIMMERMAN, E. Rules of play: game design fundamentals. Cambridge: MIT Press, 2003.

SHELDON, L. llovebees: playing and designing in real-time. In: DAVIDSON, D. et al. Well played 2.0: video games, value and meaning. 2010. p. 243-252. Disponível em: <http://www.feedbooks.com/userbook/17389.pdf>. Acesso: 11 jul. 2013.

SILVA, D. Jogos de realidade alternativa: o virtual é real. 2008. Trabalho de Conclusão de Curso (Graduação em Publicidade) - Universidade Interativa COC, Ribeirão Preto, São Paulo, 2008.

SZULBORSKI, D. This is not a game: a guide to alternate reality gaming. Santa Barbara -CA: Active Media Group, 2005.

TAVARES, R. Cyborg de carne e software: avatares e consciência nos jogos e nas redes. In: LEÃO, L. (Org.). Derivas: cartografias do ciberespaço. São Paulo: Annablume; Senac, 2004. p. 211-219 
TYCHSEN A. et al. Live action role-playing games: control, communication, storytelling, and MMORPG similarities. Games and Culture, v. 1, n. 3, p. 252-275, July. 2006.

WHYTE, W. F. Sociedade de esquina: a estrutura social de uma área urbana pobre e degradada. Tradução de Maria Lucia de Oliveira. Rio de Janeiro: Jorge Zahar, 2005.

Recebido: $27 / 02 / 2013$

Received: 02/27/2013

Aprovado: $10 / 06 / 2013$

Approved: 06/10/2013 